\title{
AC 2009-810: INSPIRING A DIVERSE POPULATION OF HIGH-SCHOOL STUDENTS TO CHOOSE ENGINEERING AS A CAREER PATH
}

\section{Katherine Chen, California Polytechnic State University}

Katherine C. Chen is Professor and Chair of the Materials Engineering Department at the California Polytechnic ("Cal Poly") State University, San Luis Obispo. She received a B.A. in Chemistry and a B.S. in Materials Science and Engineering at Michigan State University. Her Ph.D. is in Materials Science from MIT. She has strong interest in and is very active in outreach activities.

\section{Daniel Belter, California Polytechnic State University}

Daniel Belter is an undergraduate student in the Statistics Department at the California Polytechnic (Cal Poly) State University, San Luis Obispo. In addition to his formal coursework in statistics, Daniel is involved in a variety of projects, applying his statistical knowledge to address practical problems. His work on this paper was part of his Senior Project efforts.

\section{Teana Fredeen, California Polytechnic State University}

Teana A. Fredeen is the Outreach Coordinator for the College of Engineering at the California Polytechnic ("Cal Poly") State University, San Luis Obispo. She received a B.S. in Aeronautical Engineering at Cal Poly in 1991. She has worked in technical sales and marketing for 15 years in the embedded computer and telecommunications industry. For the past four years, she has been a telecommunications consultant. She is passionate about engineering outreach to K-12 students and has increased the outreach activity for Cal Poly's College of Engineering over the past year.

\section{Heather Smith, California Polytechnic State University}

Heather S. Smith is a Senior Lecturer and Statistical Consultant in the Statistics Department at the California Polytechnic (Cal Poly) State University, San Luis Obispo. She received a B.S. in Mathematics from the University of Florida and an M.S. in Statistics from the Florida State University. For seven years she worked as a statistical consultant for Westat, Inc. a research organization, in Rockville, Maryland. Thirteen years ago to she joined the Statistics faculty at Cal Poly. She is an active participant in research involving a broad range of engineering and educational projects.

\section{Shirley Magnusson, California Polytechnic State University}

Shirley J. Magnusson is a Professor of Science and Mathematics Teaching Education in the College of Education at California Polytechnic State University, San Luis Obispo. She holds an M.S. and Ph.D. in science education from the University of Iowa and the University of Maryland, respectively. She is nationally known for the development and study of student learning from novel text-based materials for use in inquiry-based instruction that were modeled after the notebooks of scientists. Her current work is exploring how to integrate engineering with science in the elementary curriculum in a way that empowers children and supports teachers in finding time to teach science. 


\title{
Inspiring a Diverse Population of High School Students to Choose Engineering as a Career Path
}

\begin{abstract}
A week-long, summer day-program was created to expose and inspire high school students to consider engineering as a career path. The goals of the program were to 1) bring high school students of diverse backgrounds to our university campus, 2) excite kids about engineering as a profession that is creative and helps society, 3) expose students to different engineering disciplines, 4) provide positive experiences with hands-on engineering activities, and 5) encourage and help prepare the young students to study engineering in college. Extensive recruiting was performed by the College of Engineering Outreach Coordinator, who visited targeted schools and developed relationships with teachers and counselors. As a result, 55\% of the program attendees were from underrepresented groups, including $29 \%$ female students. To support underrepresented and first-generation students, numerous scholarships and transportation were provided by industry partners.

Ten different engineering disciplines were highlighted as different hands-on lab activities. Current university engineering students assisted as program counselors and acted as role models to the program attendees. In addition, campus tours, industry tours, seminars, and recreational time were built into the schedule. The program culminated in a Showcase open to the public, friends, and family where the program attendees could share their experiences and display their work.

While the goals for the program were met, we also researched what type of impact the program had on the high school students. The program attendees participated in an end-of-the-week survey to assess the impact of the program in terms of their self-perceived abilities, knowledge, and attitudes towards engineering. A statistical analysis of responses on a 7 point Likert scale showed an increase in four different areas measured and quantitatively demonstrated meeting our goals. However, the survey results also revealed a great propensity of participants already interested and planning to study engineering. These results will help us to refine our goals, future marketing approaches, and development of the summer program.
\end{abstract}

\section{Introduction}

The Grand Challenges identified by the National Academy of Engineers (NAE) ${ }^{1}$ and the global nature of engineering in the $21^{\text {st }}$ century require a diverse set of engineers with innovative ideas and a mindset towards the helping society. Thus, the "Rise Above the Gathering Storm" report calls for enlarging the pipeline of students and increasing the number of bachelor's degrees in sciences and engineering. ${ }^{2}$ In efforts to diversify our university's pipeline to the College of Engineering, we offered a summer engineering program for high school students.

Engineering Days at Cal Poly University was started in 2007 as a pilot program directed by the Women's Engineering Program. Twenty students attended the camp, which was designed to introduce high school students (especially underrepresented groups) to engineering. For 2008, 
direct marketing was added to the high schools with the highest population of underrepresented groups, as indicated by the demographics of schools on the Department of Education website ${ }^{3}$. This was primarily done through classroom visits by the Outreach Coordinator and MESA program advisor. We also marketed directly to students participating in MESA programs and parents participating in the PIQE (Parent Institute for Quality Education) program ${ }^{4}$. Teachers and counselors at the high school assisted students with online applications by directing them to available computers, and providing assistance if needed. We found that speaking to students directly and telling them about engineering and the camp was the most effective. Where 1-2 students may have had an interest prior to a classroom visit, more than ten were typically interested after a 15 minute talk was given.

Scholarship money was available, and all students applying for a scholarship received at least $50 \%$ of the cost of the camp, which was only $\$ 200$ per student. Distribution was pre-determined, based on a scale of income levels. With the exception of the very low income students who received full scholarships, most students were required to pay at least $\$ 20$ to ensure a commitment to the program. Over $\$ 9,000$ in scholarships were awarded to approximately half of the attendees. By targeting those schools with a large underrepresented population and by providing scholarships and transportation, we were able to draw a diverse group of students and 93 students attended the week-long program.

\section{Defining the goals of the summer program}

The desired outcomes and long-term goals of the Engineering Days summer program were to:

- increase the pipeline of students studying engineering

- increase the diversity of students studying engineering

- increase the pool of students applying to Cal Poly university in engineering

With these outcomes in mind, as well as the common reported reasons for not choosing engineering, we developed specific goals for the program:

1) bring high school students of diverse backgrounds to our university campus

2) excite kids about engineering as a profession that is creative and helps society

3) expose students to different engineering disciplines

4) provide positive experiences with hands-on engineering activities, and

5) encourage and help prepare the participants to study engineering in college.

We also wanted to assess the program to measure the impact of Engineering Days on the participants, and to have a mechanism to guide improvements for future offerings. Details of the survey are in the Procedures section.

\section{Structuring the summer engineering program}

The Engineering Days program was designed and structured by a team of Cal Poly faculty and students, and similar to existing programs elsewhere 5 . The week long program was designed to maximize the time in hands-on labs. The lab activities were designed by Cal Poly professors who already practice the university's philosophy of "learn by doing," and thus the activities were interactive and lectures were minimized (Figure 1). Using a breadth model, versus a depth model, the program gave students exposure to as many as seven engineering disciplines and as few as five. Many engineering summer programs focus on one type of engineering, such as 
robotics or computer gaming, and build a depth of knowledge in a smaller number of students. Since this program's goal was to increase the number of students who choose to study engineering, we developed a program for students to consider a variety of different engineering careers. It was crucial that the program be open and non-threatening to students who were not in the top $10-20 \%$ of their class.

a)

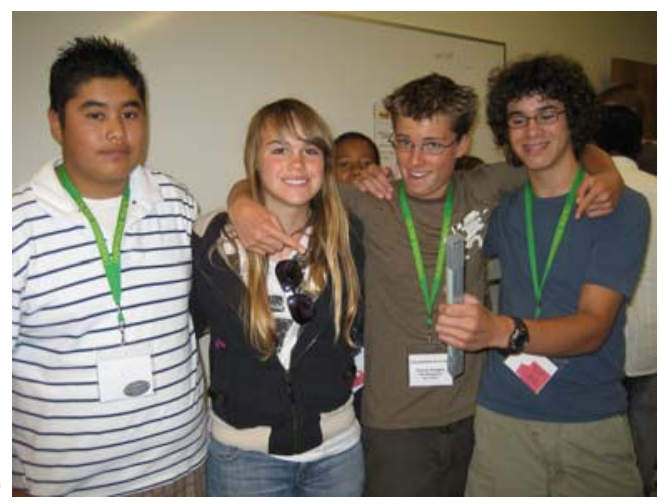

b)

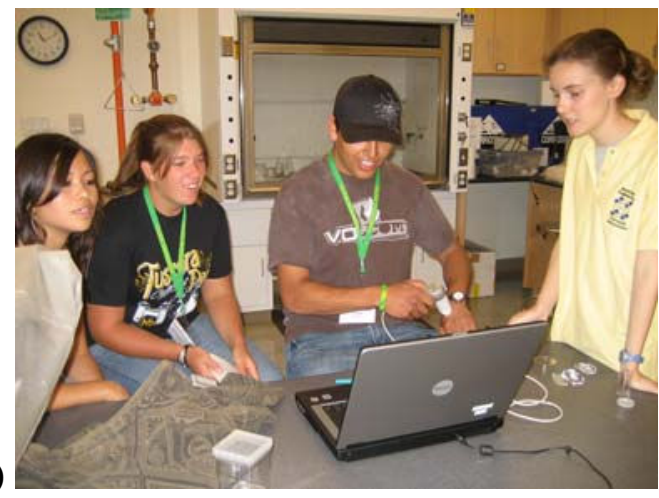

Figure 1. Engineering Days Materials Engineering lab activities were team oriented and hands-on experiences, as in a) the design and testing of a prototype hockey stick and b) exploration of materials in everyday life and at the micro-scale.

In addition to the lab time, the program needed to inspire the students by exposing them to exciting real-world engineering applications. Tours of the campus engineering labs and local engineering-based companies were added to the program, along with guest speakers working in the engineering field. Presentations from the university admissions department were added to provide detailed information to prepare for college enrollment. This proved to be highly effective and $73 \%$ of the students rated the admissions presentation as "important" or "very important" to their experience.

Another feature was to prepare students for college was a personal development workshop on networking. The networking presentation was developed by collegiate counselors and showed students how to use networking to help find a job, internship or reference for college through a presentation, skit and role-playing. The students were each given a notebook and pen in which they could begin collecting contacts throughout the week. The students rated this workshop highly, with only 3 students indicating it as "not very important." The only negative feedback on this workshop is that it wasn't scheduled earlier in the week. Each group of students was lead by a current college engineering student, who also acted as a role model. A collegiate panel was also provided as an opportunity for the students to ask specific questions about college, a particular major or the college student's decisions for choosing his/her major.

Finally, the program needed to be fun for the students to return or to recommend the program to their peers. We didn't want the program to promote any misconceptions or stereotypes about engineering. We wanted students to see that engineers are made from all types of people, and that engineers have fun too! Ice breakers, an improvisational comedy group, games and half a day of fun time on campus were part of the schedule. 
For the fun time, students bowled, did rock climbing, played Rock Band and ate at the on-campus pizza restaurant. Not only did this provide a break from the time in the labs, it also provided valuable bonding time for the groups.

\section{Procedures}

A survey was developed for the end of the Engineering Days summer program to assess the impact of the program in achieving the set goals. Data on the students serviced was also desired to better understand their self-perceived abilities, motivations and goals. The underlying thesis is that the essential components to choosing engineering as a profession are the understanding of what the field is and making the plans to study engineering. As precursors to those decisions, individuals must also have the confidence in their abilities. Furthermore, they must be able to see themselves practicing engineering as a career.

We decided to focus on the engineering profession ${ }^{6}$, rather than the engineering field, and thus the survey statements (Table I) reflect personal declarations that lead to career selection. Some of the statements deal with the self visualization of being an engineer. Many females tend to lack the confidence or fail to identify with the field (due to lack of role models or inaccurate stereotypes).

Table I. Statements on the Engineering Days survey and the corresponding coded variable for study

\begin{tabular}{|l|l|}
\hline Survey statement & Variable \\
\hline "I understand what an engineer does." & understood \\
\hline "I plan to study engineering in college." & study engr \\
\hline "I have confidence in my ability to be an engineer." & confidence \\
\hline "I can picture myself working as an engineer as a career." & picture \\
\hline
\end{tabular}

The program participants were asked to circle a number that best described themselves on a 7-point Likert scale, as follows:

$\begin{array}{ccccccc}1 & 2 & 3 & 4 & 5 & 6 & 7 \\ \begin{array}{c}\text { not at all } \\ \text { true of me }\end{array} & & & & & & \\ \text { very true } \\ \text { of me }\end{array}$

The statements were to be rated before and after their experiences with Engineering Days. However, in full disclosure, the data from this comparative study before and after the program are inherently flawed. Due to problematic logistics and timing (which can be avoided in the future), we were unable to actually have the participants answer the survey questions before the program. Instead, the survey asked the participants to rate their level of agreement to statements before and after the program on the same survey. While the procedure is nonstandard in statistics, it required the participant to judge their own perception of the impact of the summer program. We feel that there are still important and valid results that emerge. 
In addition, we also asked open-ended questions to check the consistency of the survey results. The questions were as follows:

1. How would you explain engineering to a friend (that didn't attend the camp)?

2. What do you know about engineering now that you did not know before Engineering Days?

3. What is the most significant thing that you learned about yourself at Engineering Days?

4. a) What are your goals for academics?

b) What are your goals for life?

The statistical methods employed to summarize and analyze the survey data included correlation, t-tests, Chi-squared tests, and Analysis of Variance tests (ANOVA). The graphical methods include pie charts, bar charts, scatter plots, and individual value plots.

\section{Results and Discussion}

\section{Assessing the program - the demographics}

While 93 students attended the Engineering Days program, the data and results reflect only $89(96 \%)$ of the students who completed the consent form. One of the top goals of the program was to bring high school students of diverse backgrounds to our university campus. As seen in Figure 2a, 55\% of the program attendees identified themselves as non-White (with $45 \%$ being Hispanic). Females represented $30 \%$ of the students (Figure $2 \mathrm{~b}$ ). The percentages of the underrepresented groups at the Engineering Days program exceed the percentages of the current engineering students at Cal Poly University (Table II). The success in providing the program to a diverse audience aligns with our university's mission. Longitudinal studies are in the works to determine how many program participants apply and enroll at Cal Poly, as well as those who major in engineering.

a)

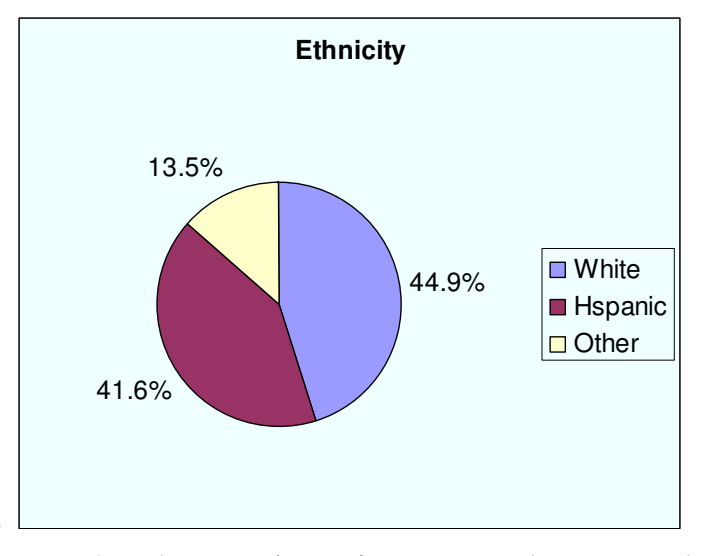

b)

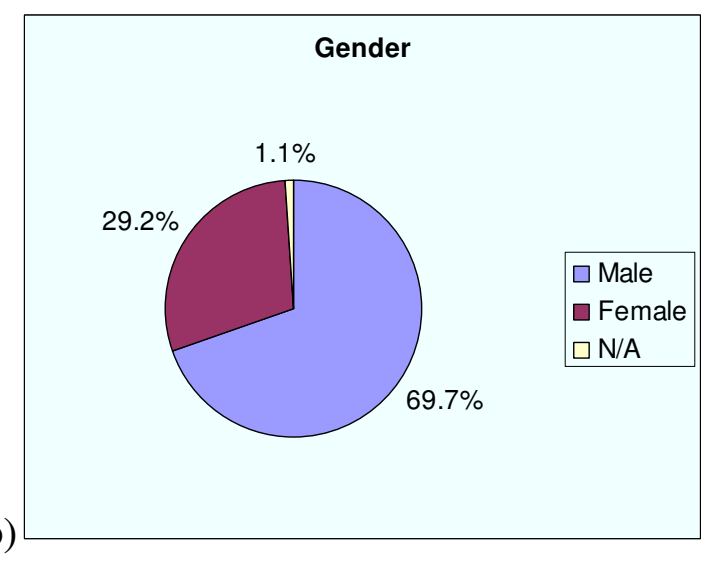

Figure 2. The Engineering Days demographics of the program participants were a) $55 \%$ non-White and b) $29 \%$ female. 
Table II. Comparison of the percentages of underrepresented groups in the Engineering Days program and in the College of Engineering at Cal Poly.

\begin{tabular}{|l|c|c|}
\hline $\begin{array}{l}\text { Underrepresented } \\
\text { group in Engineering }\end{array}$ & $\begin{array}{l}\text { Engineering Days } \\
\text { summer program students }\end{array}$ & $\begin{array}{l}\text { Cal Poly Engineering } \\
\text { students }^{7} \text { (F07 data) }\end{array}$ \\
\hline non-White ethnicity & $55 \%$ & $32 \%$ \\
\hline Females & $29 \%$ & $13.6 \%$ \\
\hline
\end{tabular}

Most of the program attendees (79\%) were within a 40 mile radius of the university (Figure 3), and did indeed, come from the targeted audience. Participants outside the 40 mile radius learned of the program from the web site or from word of mouth. Critical to the program's success of attracting and servicing our targeted populations was providing transportation and scholarships.

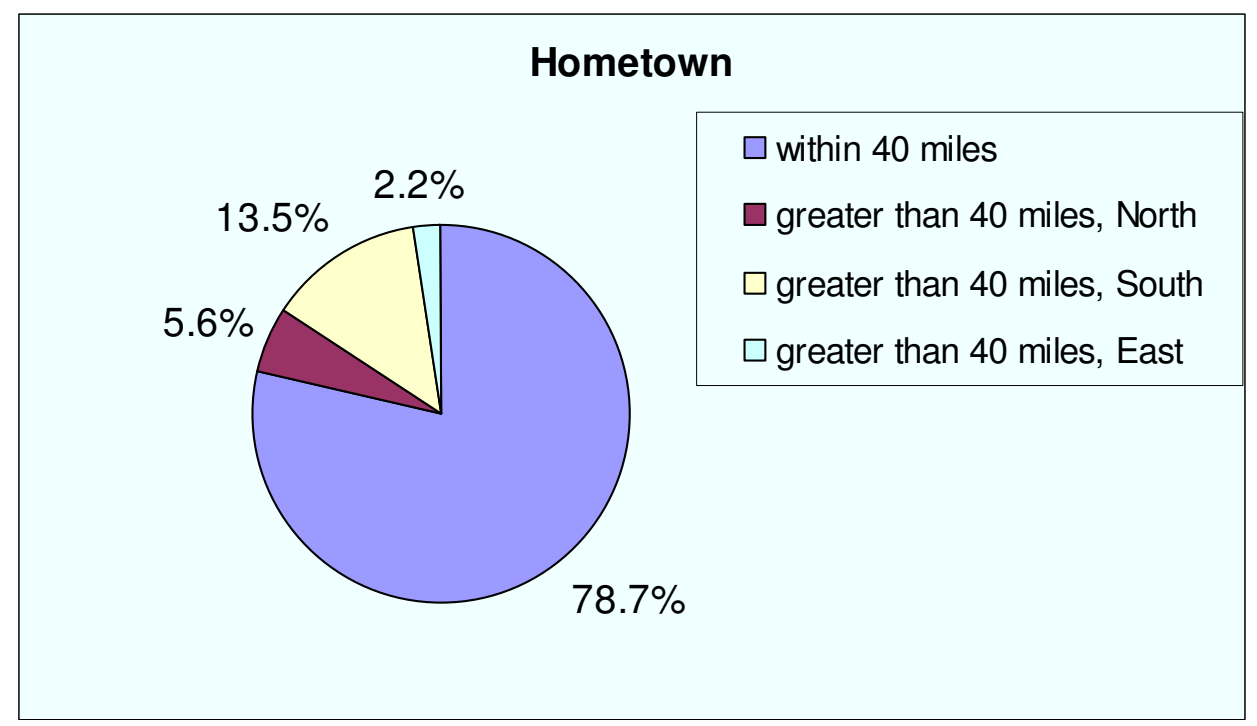

Figure 3. The majority of the students came within a 40 mile radius and were from the targeted schools.

We also attempted to target potential First Generation College students. From our surveys, it turned out that $75 \%$ of the attendees had a family member (parent or sibling) that was college educated or currently in college. Furthermore, $30 \%$ of the students reported that they had a family member who is an engineer (and some even had both parents as engineers!). While we don't have the corresponding percentages for high school students in the targeted schools (as a control group), we believe that these percentages for family members that are college-educated and/or engineers are higher for the program attendees. We will be gathering such data from the high school classes that we visit, and will strategize how to reach other students in the coming year. Figure 4 is a picture of all the Engineering Days participants and their collegiate mentors. 


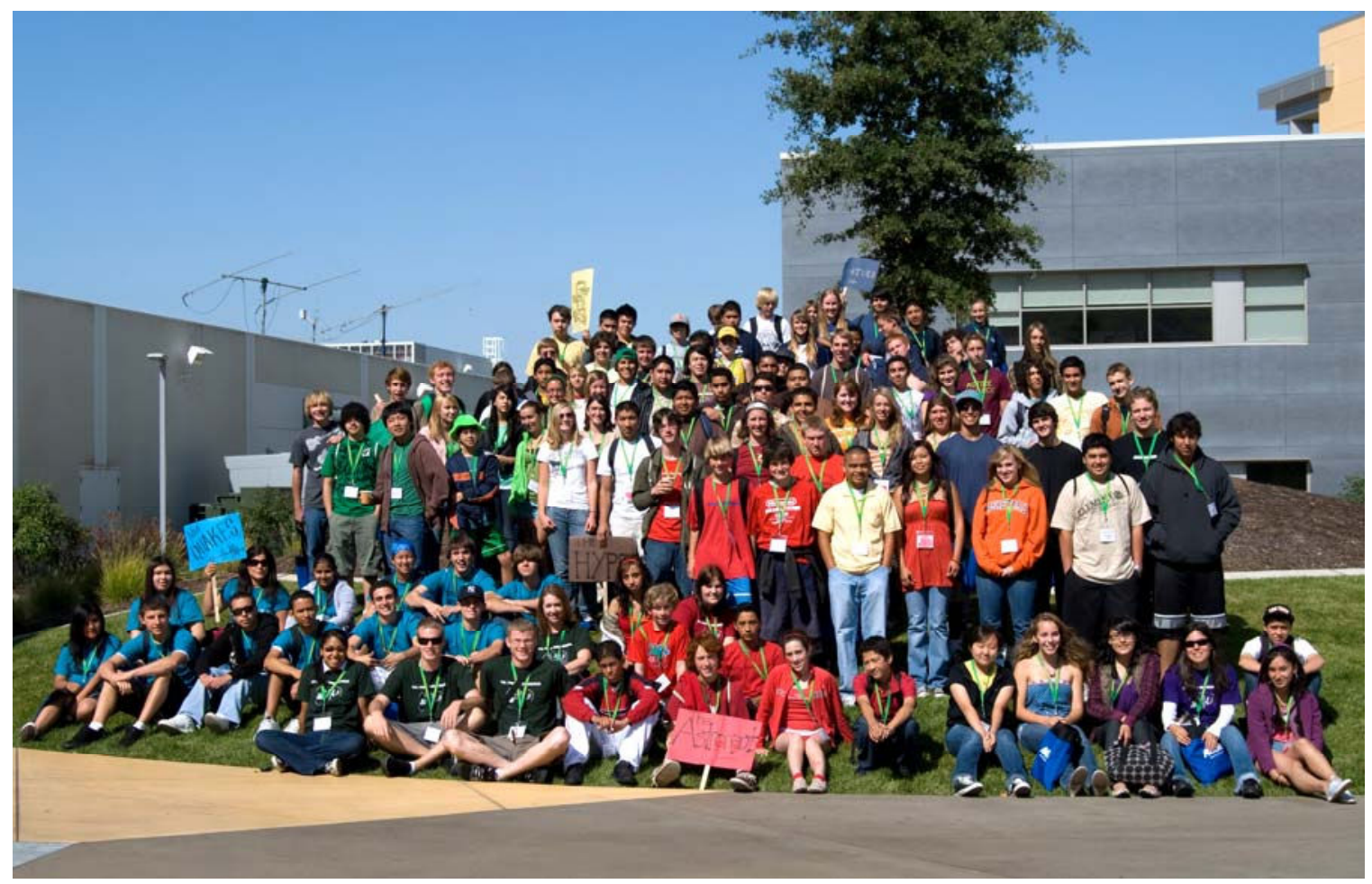

Figure 4. The 2008 Engineering Days summer program participants and collegiate mentors.

\section{Assessing the program - meeting the goals of Engineering Days}

While it is difficult to quantify "excitement," "enjoyment," or "inspiration," we decided to measure student satisfaction of the program through the statements of whether they planned to attend the program the following year (if they were not a high school senior), and if they would recommend the program to a friend. $88 \%$ responded positively to attending the program again, and $97 \%$ reported that they would recommend the program. In the open-ended section of the survey, several times students responded in the vein that "Engineering is really cool" or that engineering is "fun, interesting." The high level of enthusiasm was felt by the program staff and instructors. The participants appeared to be very eager for the activities.

Another goal of the program was to excite young students about engineering as a profession that is creative and helps society. Throughout the week, the program coordinator expressed the message that "engineers make the world go around" and many students repeated the tagline. How the participants actually envision and interpret this statement should be assessed in the future. Different lab activities emphasized different aspects of engineering, but not all had a focus on helping society.

An additional program goal was to expose students to different engineering disciplines. Each participant experienced at least 5 different lab activities, sometimes 2 different activities within the same engineering discipline. From interactions and discussions with 
the program attendees, it became quite apparent that many were trying to distinguish among the different engineering disciplines in order to decide which to study in college. For instance, some students did lab activities in Architectural Engineering and Civil Engineering. In other cases, students were exposed to engineering disciplines (such as Materials Engineering) that they had no previous knowledge of.

From the open-ended survey question, "What do you know about engineering now that you did not know before Engineering Days?,” the vast majority of participants (41\%) answered that they now know that there are several types of engineering. The question itself was left vague on purpose to see how students would answer. The responses were then binned into 8 different groups, and other responses included knowing what engineers do, what the job opportunities are, and that engineering is innovation.

Our goal of providing positive experiences with hands-on engineering activities was also assessed through individual lab activity surveys conducted at the end of the labs. All the averages and ranges for the ratings were similar for the different lab activities, and thus the questions and results are not included in this paper. One of the hallmarks of our university is to "learn by doing" with active, hands-on approaches, and thus the high marks are not surprising. Although the high scores for the individual lab activities were reassuring, we plan to rework the survey to garner more useful information. For instance, written feedback indicated that the participants did not always enjoy lectures that proceeded lab activities and the lectures could perhaps be shortened in the future.

To reinforce the positive engineering experiences for the week, the program closed with a Showcase event. The young students were able to share with their families what they had built and accomplished during the week (e.g., rocket, hockey stick prototype, solar water heater, circuit board). The event was designed to allow the students to show pride and educate their family. A surprise visit and speech by the university president added to the showcase event!

\section{Assessing the program - investigating the perceptions of self and engineering}

The four statements about the students' self-perceived abilities, knowledge, and attitudes towards engineering (Table II) were studied in relation to the change before and after the Engineering Days program. A positive change or increase in the Likert scale rating is associated with a positive impact and a desired result, while a negative change signifies an adverse result. The results are displayed as distributions in Figure 5 and as a scatter plot in Figure 6. 
a)

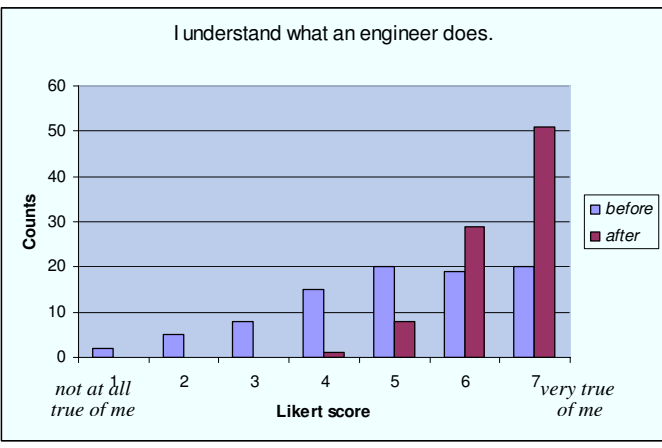

c)

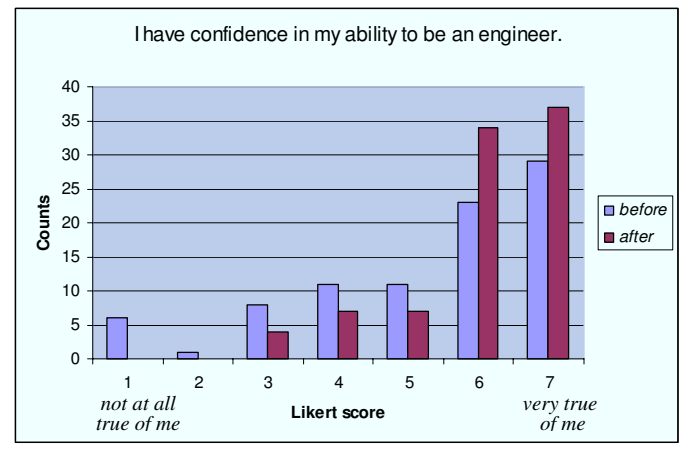

b)

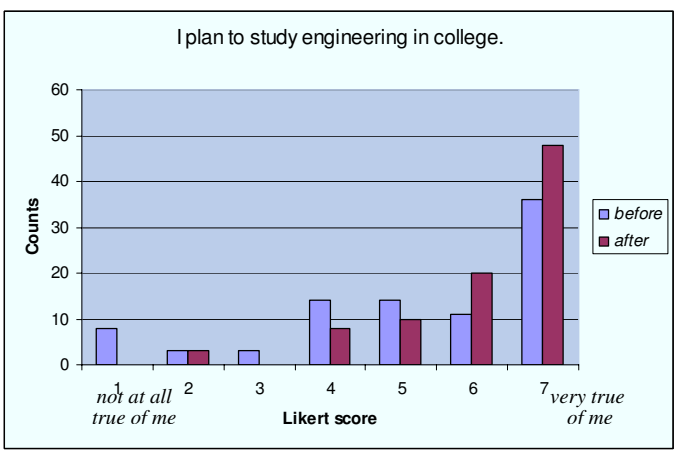

d)

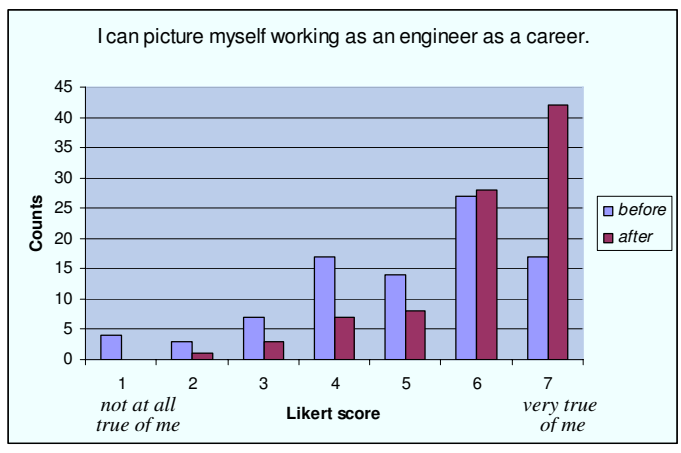

Figure 5. Histograms of the response rates of Likert scores from the four survey statements before and after the program to measure the self-perception of the understanding, plans to study, and confidence in engineering.

The distribution of responses for each survey statement before and after the program is shown in Figure 5. An increase in the responses on the Likert scale is evident for all the statements. An interesting observation is that the ratings start out relatively high on the scale of 7. Further statistical analysis was performed to determine any significant gains and associations.

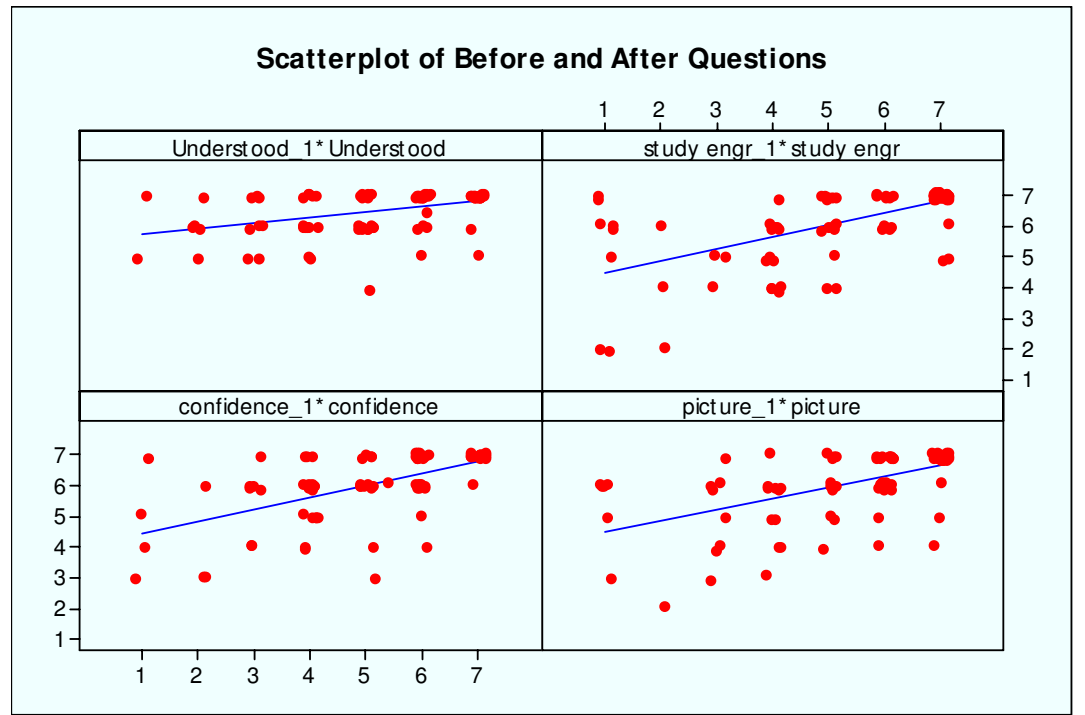

Figure 6. Scatter plot of the responses to the four survey statements to investigate any associations between the before and after responses. 
In Figure 6, the before responses are on the x-axis and the after responses are on the yaxis. We can see that there is a positive, moderate to strong association between the before and after statements. This result is expected as the goals of the program were imbedded in the survey statements. Similar results are seen with other programs ${ }^{8}$. The graph also shows that students who score themselves lower on the before statements tend to also score themselves lower on the after statements. The range of before responses is generally greater than the range for after responses.

A matrix plot (not shown) was used to assess the association among several pairs of variables at once. Every question had a moderate to strong association with one another. As expected, understanding, confidence, planning to study, and picturing oneself as an engineer are all related.

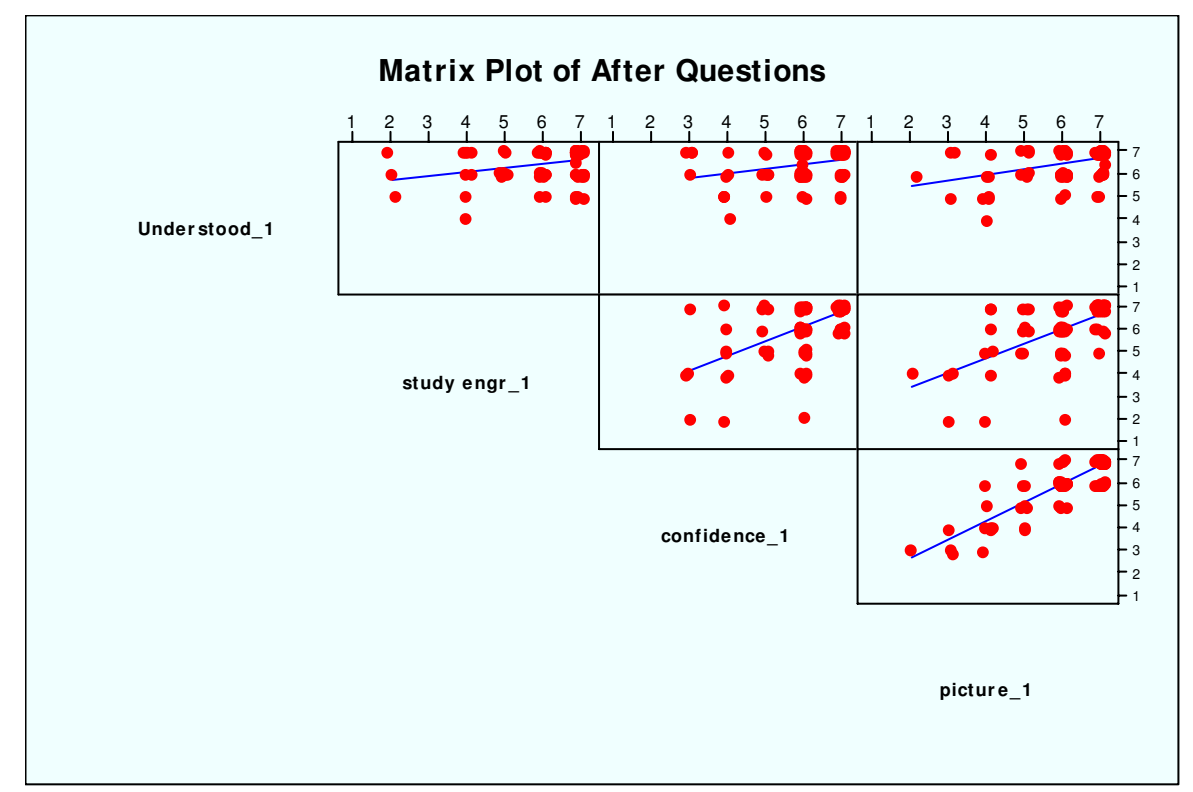

Figure 7. Matrix plot assess associations or relationships of the 4 different variables with the after responses.

In Figure 7, we assess the relationships among the variables within the after statements. All the variables have a moderate to strong association. The confidence in ability to be an engineer had the strongest association with picturing themselves as an engineer. The r-value is .866, and as a general rule, a value this close to 1 signifies that there is a strong association between the two variables. The result is consistent with the theory that confidence in ability is needed to see oneself as an engineer. However, these items do not necessarily translate to a person pursuing an engineering field. In other words, confidence is a necessary but not sufficient condition. 


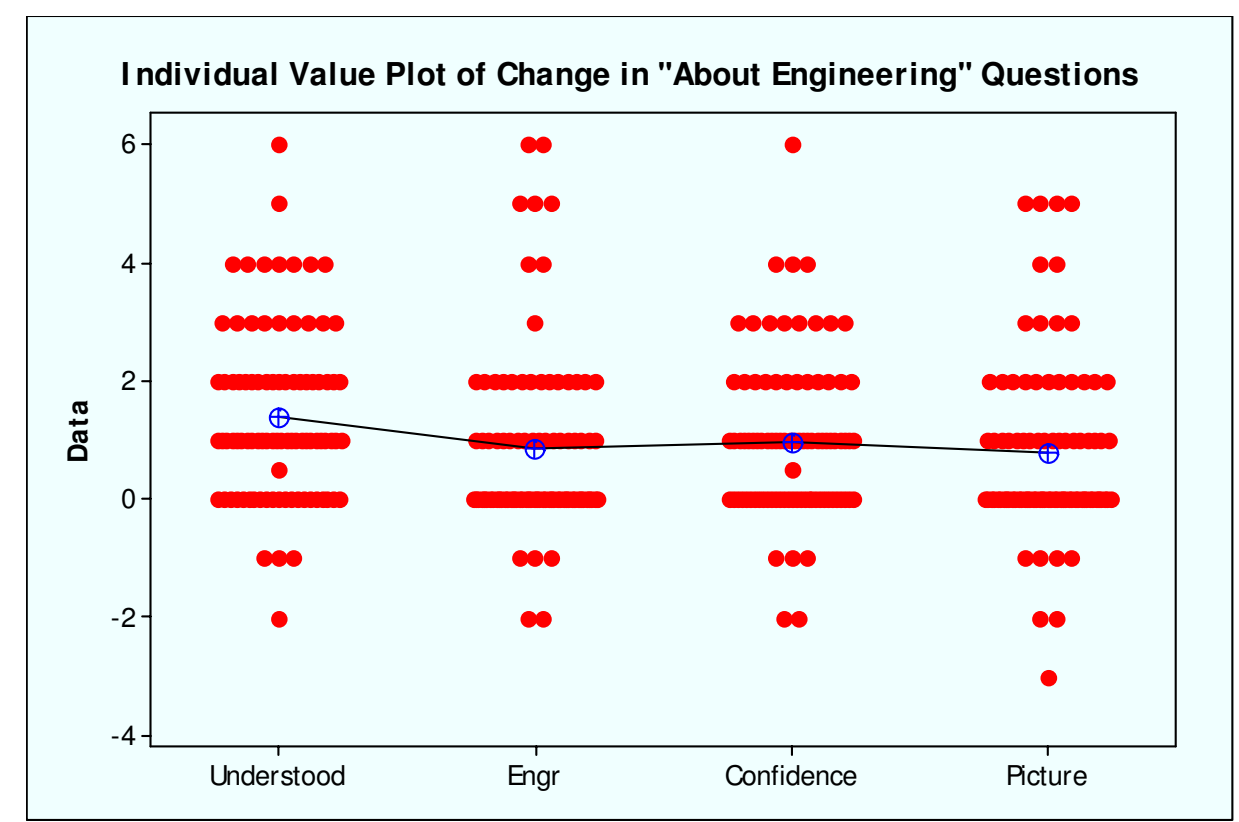

Figure 8. Plot of the changes in response scale for the 4 different statements.

Figure 8 is an Individual Value Plot of the change in ratings (i.e., the after score minus the before score) that compares sample distributions by plotting individual values for each variable or group in a vertical column, making it easy to spot outliers and see the distribution. The average in the net change in Likert scale ratings is also plotted. Again, we can see that a majority of the values are greater than zero. This plot indicates that there has been a positive change on average after the experiences with Engineering Days. There are only a few occurrences of a negative or adverse effect, and some of the counts in "no change" can be attributed to before scores already at 7.

The means or averages of the change in the statements are in Table III. A One-sample ttest was performed on each variable, and each p-value returned was 0.000 . Thus, the means of the difference variables are greater than 0 not by chance alone, and indeed, a positive change from the program is evident.

Table III. Means and standard deviations of the differences in the after and before statements on the Engineering Days program.

\begin{tabular}{|l|c|l|}
\hline Variable & Mean difference & StDev \\
\hline Understood & 1.410 & 1.455 \\
\hline Study & 0.865 & 1.531 \\
\hline Confidence & 0.983 & 1.337 \\
\hline Picture & 0.775 & 1.498 \\
\hline
\end{tabular}


A One-Way ANOVA was conducted on the means to compare the equality of more than two means, versus them not all being equal. Basically, the test was conducted to see if any of the variables had a significantly larger change than the others. A p-value of 0.020 resulted, and indicates that at least one of the means in Table III is significantly different from the rest. From Tukey's comparisons, the difference in the mean of the "understood" variable is, on average, significantly higher than the mean difference in the "picture" variable. One interpretation of these results may be that the largest impact of the Engineering Days program was that the participants felt that they better understood what engineering is (whether it is in what engineers do or the different engineering disciplines).

Binning of the responses into categorical variables was performed to investigate whether the way participants responded in the after statements depended on their initial before statements. We wanted to see if individuals starting out with low ratings had different changes than those with higher ratings. For instance, if a participant had already rated themselves at 7, there could be no positive change. Also, it seemed that more of an impact (i.e., larger change) would be possible for those starting out with low ratings. However, 4 separate Chi-squared tests resulted in p-values above 0.05 , and we failed to reject the null hypothesis that the way the students answered in the after statements does not depend on their answers on the before statements.

However, analysis of the raw data shows that a high percentage of participants (44-58\%) were already rating themselves at 6 or 7 on the before statements. These high ratings of the before statements lends credence to the supposition that the program participants were already inclined towards engineering. The percentage of participants scoring themselves at 1 or 2 with the before statements ranged from $8-12 \%$.

On very few occasions, the change in ratings was negative, indicating a negative impact. The low ratings before continued with low ratings after. While low before ratings would be opportunities to make large positive impacts in regards to the program goals, the population started out quite small. Some of these participants may have been attending due to parents influence or to keep a friend company (as revealed in private communications). However, discovering that one does not want to be an engineer is also an acceptable outcome and helps the student learn more about themselves. Some of the written comments that engineering "is super hard" are consistent with other findings of why students do not choose engineering to study.

Several analyses were run to investigate whether demographic characteristics or enjoyment of the program were predictive of the statement responses described above. All manners of comparisons were made and only three statistically significant relationships were found in the more than 60 individual comparisons investigated. These are described below, however, none of these three findings are highly statistically significant.

- Having a family member with college experience is related to whether the student plans to study engineering. Those that answered yes to a family member with college experience shows a statistically significant lower interest in studying engineering in 
the future. The p-value of .031 gives weak to moderate evidence to back this claim. Such a result is actually surprising since many studies show that engineering students often have a family member that is an engineer. A possible explanation is that some program participants were pressured to attend or that they were planning other fields of study (e.g., medicine).

- The difference in the responses of the before statements from the after statements are statistically different from the responses to whether the student would suggest Engineering Days to a friend. Those that did not rate their understanding of what an engineer does strongly did not want to suggest Engineering Days to a friend. The pvalue for this test is .034 which gives evidence to support this claim. However, there were only 3 students who said they would not suggest this program to a friend.

- Having a family member with college experience is related to the gender of the student. Female students answered yes to a family member with college experience statistically more than that of males. The p-value is .05 and gives weak evidence to support this claim. However, college educated families tend to value higher education and be more supportive of educational goals of females.

Reviewing the collective results of the demographics and responses, we are left with the question of how much of an impact did we really have on the intended population? Did we convince anyone to pursue engineering that wasn't already considering engineering? Perhaps a positive impact was made on some of the younger participants who had not yet decided on what they wanted to study. Many educators feel that by high school, students are already on a particular track and that middle school is the better target to influence interests.

From multiple parts of the study, large numbers of students appeared to be already inclined towards engineering. We should be rethinking the goals and strategies of our summer program. While we want to encourage students who are already thinking of studying engineering and to apply to our university, we would also like to have a bigger impact by inspiring those that are not necessarily considering engineering at the moment.

\section{Planning for the future}

The assessment of the program at its infancy has allowed us to discover areas needing more study to make improvements. In order to better understand our local demographics, the Outreach Coordinator will be working with area teachers to survey the students and baseline the demographics of the general population. We plan to conduct longitudinal studies to measure how many program participants choose engineering to study, how many apply to Cal Poly, and how many enroll in engineering at Cal Poly.

Organizers of the program will also revisit the desired goals and outcomes. The marketing and targets for the program (i.e., middle school or high school students) would follow accordingly. The message about engineering (e.g., creative endeavor that helps people) should also be revisited to create a program that is uniform and consistent with its lab activities. 


\section{Conclusions}

Overall, the Engineering Days summer program was successful in serving students of underrepresented groups. The combination of different hands-on laboratory activities, industry tours, speakers, and fun activities all contributed to the positive experience the students reported. While the survey indicated an increase in their understanding of what engineers do, plan to study engineering in college, and confidence to be an engineer, we also noted that most of the participants were already starting out very high in those areas. We suspect that we may have attracted students already interested in engineering, and discovered that many of the participants were trying to distinguish the different types of engineering during the program. Follow up assessment with the participants is planned, and revisions of our summer program will take place based on these results.

\section{Bibliography}

${ }^{1}$ www.engineeringchallenges.org

${ }^{2}$ Rising Above the Gathering Storm: Energizing and Employing America for a Brighter Economic Future http://books.nap.edu/catalog/11463.html

${ }^{3}$ http://www.ed.gov/index.jhtml

${ }^{4}$ http://www.piqe.org/

${ }^{5}$ A.M. Ogilvie, "Capturing Young MINDS with MITE - A Pre-College Residential Program Generating Results," Proceedings of the 2005 ASEE Annucal Conference and Exposition, 2005.

${ }^{6}$ D. Bee, B. Puck, and P. Heimdahl, "Ten Years of STEPS Success: Significant Impact in Attracting Girls to Science, Technology, and Engineering Careers," Proceedings of the 2007 ASEE Annucal Conference and Exposition, 2007.

${ }^{7}$ Cal Poly University Fall 2007 Fact Book.

${ }^{8}$ J. Hubelbank, C. Demetry, S.E. Nicholson, S. Blaisdell, P. Quinn, E. Rosenthal, S. Sontgerath, "Longterm Effects of a Middle School Engineering Outreach Program for Girls: A Controlled Study,"

Proceedings of the 2007 ASEE Annucal Conference and Exposition, 2007. 